\title{
Alfentanil and patient-controlled propofol sedation - facilitate gynaecological outpatient surgery with increased risk of respiratory events
}

\author{
A Nilsson, Lennart Nilsson, E Ustaal and Folke Sjöberg
}

\section{Linköping University Post Print}

N.B.: When citing this work, cite the original article.

This is the authors' version of the following article:

A Nilsson, Lennart Nilsson, E Ustaal and Folke Sjöberg, Alfentanil and patient-controlled propofol sedation - facilitate gynaecological outpatient surgery with increased risk of respiratory events, 2012, Acta Anaesthesiologica Scandinavica, (56), 9, 1123-1129.

which has been published in final form at:

http://dx.doi.org/10.1111/j.1399-6576.2012.02749.x

Copyright: Wiley-Blackwell

http://eu.wiley.com/WileyCDA/Brand/id-35.html

Postprint available at: Linköping University Electronic Press

http://urn.kb.se/resolve?urn=urn:nbn:se:liu:diva-84741 


\section{Alfentanil added to patient-controlled propofol sedation facilitates gynecological outpatient surgery at the expense of an increased risk of respiratory events}

\section{Short: Patient-controlled sedation for gynecological operations}

Andreas Nilsson $^{1,2}$, Lena Nilsson ${ }^{1,2}$, Eva Ustaal $^{3}$, Folke Sjöberg ${ }^{1,4}$

${ }^{1}$ Department of Anesthesiology and Intensive care, Linköping University Hospital, 58185 Linköping, Sweden

${ }^{2}$ Department of Medical and Health Sciences, Linköping University, 58185 Linköping, Sweden

${ }^{3}$ Department of Obstetrics and Gynecology, Linköping University Hospital, 58185 Linköping, Sweden

${ }^{4}$ Department of Clinical and Experimental Medicine, Linköping University, 58185 Linköping, Sweden

Corresponding author: Andreas Nilsson, CRNA, PhD-stud

Department of Anesthesiology and Intensive care, Division of Perioperative medicine,

Linköping University Hospital, 58185 Linköping, Sweden

E-mail: andreas.nilsson@lio.se Phone: +46 10103 3635, fax: +46 101032836

Words count: 2847 


\section{Abstract}

Background: Widespread use of patient-controlled sedation (PCS) demands simplicity and a predictable outcome. We evaluated patients' safety and ease of use of PCS for gynecological outpatient procedures.

Methods: In a prospective double-blind study 165 patients were randomized to use propofol or propofol with alfentanil as PCS combined with local anesthetic for pain control. Data on cardiopulmonary function, consciousness, and need for interventions were collected at baseline and every fifth minute. The surgeons' evaluation of the ease and the duration of the procedure were recorded.

Results: One hundred and fifty-five patients used PCS for the entire procedure, 76 patients propofol and 79 patients propofol/alfentanil. Fifteen procedures in the propofol group were limited or could not be done, compared with four in the propofol/alfentanil group $(p=0.02)$. The duration of surgery was not affected. The addition of alfentanil affected respiratory function compared with the propofol group: 5 patients compared with none were manually ventilated $(p=0.03)$, and two-thirds compared with a quarter, were given supplementary oxygen as their saturation decreased below 90\% $(p<0.001)$. Overall cardiovascular stability was maintained. The propofol group had deeper conscious sedation as measured by the bispectral index $(p=0.03)$, but all patients could be roused. In the propofol/alfentanil group 5 patients became apneic and could not be roused.

Conclusions: PCS using propofol alone supports patients' safety, as the addition of alfentanil increased the need for specific interventions to maintain respiratory stability. However, alfentanil increases the feasibility of the procedure, as complementary doses of propofol were not required. 


\section{Introduction}

Surgical operations for minor gynecological conditions are common and often done in outpatient clinics. Local anesthesia is widely used, sometimes combined with propofol alone, ${ }^{1}$ or propofol and remifentanil. ${ }^{2}$ The need to improve effectiveness and quality has led to the more extensive use of propofol. Moderate sedation has also been claimed to be an alternative to general anesthesia. ${ }^{3,4}$ American ${ }^{5}$ and European guidelines ${ }^{6}$ give specified recommendations for the use of propofol by doctors who are not anesthetists. However, the use of propofol increases the risk of over-sedation and cardio respiratory instability. ${ }^{7}$

Propofol given by patient-controlled sedation (PCS) may be an alternative for moderate sedation for gynecological procedures outside the anesthetic room. Although PCS has been reported as safe ${ }^{8,9}$ and studies on propofol PCS commonly have used opioid supplements for pain control ${ }^{10-12}$, the impact of opioids for PCS on safety and ease of treatment has not been sufficiently evaluated. PCS seems to decrease doses of sedatives and analgesics compared to sedation by anesthetists.

Widespread use of PCS demands simplicity and a predictable outcome. Our main objective was to evaluate the safety and ease of treatment by randomized use of propofol or propofol/alfentanil for gynecological outpatient procedures. Primary, we hypothesised that alfentanil would increase the need for specific anesthetic interventions in order to maintain cardio respiratory stability. Secondary, we believed that because of the use of local anesthesia for pain control, alfentanil would not improve conditions for surgery. 


\section{Methods}

Between January 2009 and January 2010, 155 ASA class I - III patients aged between 28 and 84 years old completed this prospective, controlled, randomized, double-blind study. They were treated for incontinence, anterior or posterior repair, or combinations of reconstructive genital surgery (Table 1). Exclusion criteria comprised clinical evidence of heart failure, severe pulmonary disease, pregnancy, allergy to propofol or soya beans, or communication problems. The CONSORT flowchart describes the exclusion of patients during the trial (Fig.

1). The study took place at a University Hospital Gynecological Outpatient Clinic in an operating theatre, after approval from the local ethics committee, and written consent had been obtained from all patients. All procedures were elective, and done or supervised by consultant gynecologists. A nurse anesthetist was present through the whole study period and responsible for the study protocol, surveillance, the PCS-pump, and the safety of the patients, and a consultant anesthetist was immediately available. All patients were examined and found eligible for outpatient surgery by consultant gynecologists, in some cases after consultation with the anesthetist. Patients' characteristics are shown in Table 1. Patients were informed about the procedure, the study and concept of PCS by telephone by a nurse and a nurse anesthetist. They were instructed to fast for 6 hours before operation and to take $1000 \mathrm{mg}$ of paracetamol and $50 \mathrm{mg}$ of diclofenac one hour before surgery. On arrival the patients were given an infusion of $25 \mathrm{mg} / \mathrm{ml}$ glucose $100 \mathrm{ml} /$ hour. Routine preoperative checks were made according to the WHO recommendations for safe surgery. ${ }^{13}$ 
Figure 1. CONSORT flowchart

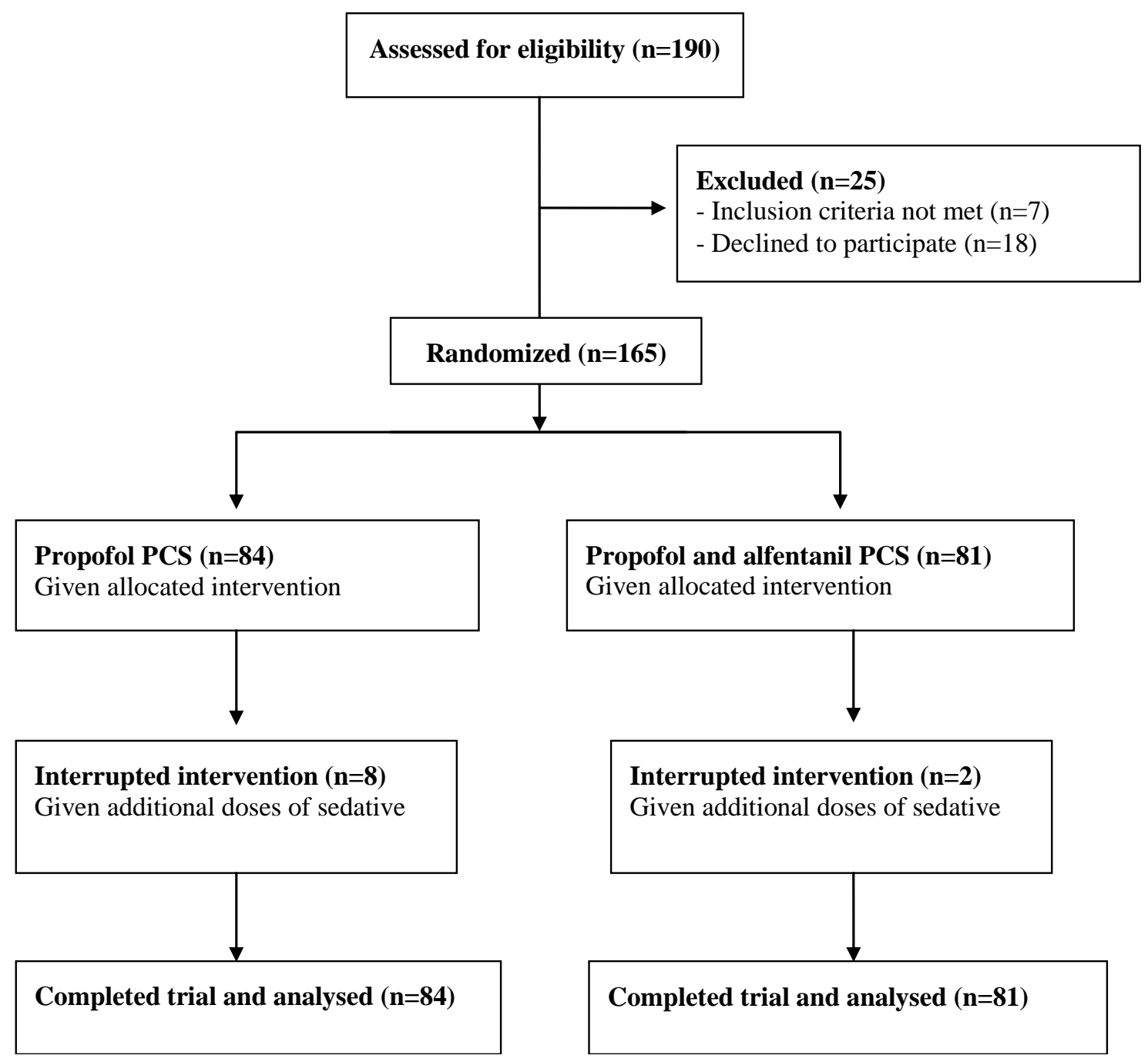


Table 1: Characteristics of patients and number of procedures. Data are mean (SD) or number.

\begin{tabular}{|c|c|c|c|c|}
\hline & & $\begin{array}{l}\text { Propofol } \\
n=76\end{array}$ & $\begin{array}{l}\text { Propofol/alfentanil } \\
\mathrm{n}=79\end{array}$ & $P$ value \\
\hline Age (years) & & $57(14)$ & $56(13)$ & 0.68 \\
\hline Weight (kg) & & $70(14)$ & $72(14)$ & 0.29 \\
\hline ASA physical status: I/II/III & & $51 / 25 / 0$ & $47 / 30 / 2$ & \\
\hline \multicolumn{5}{|l|}{ Operation } \\
\hline & Incontinence & 27 & 31 & 0.63 \\
\hline & Anterior repair & 15 & 22 & 0.24 \\
\hline & Posterior repair & 15 & 15 & 0.91 \\
\hline & Combinations & 18 & 12 & 0.18 \\
\hline
\end{tabular}

The per-operative monitoring consisted of pulse oximetry, non-invasive blood pressure measurement, electrocardiogram (ECG), respiratory rate, end-tidal carbon dioxide (IntelliVue MP30 Philips Healthcare, Best, the Netherlands), transcutaneous carbon dioxide (TCM-3 TINA, Radiometer, Copenhagen, Denmark), and bispectral index (A-2000 BIS ${ }^{\mathrm{TM}}$ Aspect Medical Systems, Natick, MA, USA). The Observer's Assessment of Alertness/Sedation scale ${ }^{14}$ were used to identify episodes of over-sedation (score 1). Obstruction of the airway was graded $1=$ clear and patient talking, $2=$ snoring, and 3=obstructed. All patients wore an open airway mask (Oxymask Plus, MedCore, Kista, Sweden). Oxymask Plus provided end-tidal $\mathrm{CO}_{2}$ sampling, but from the start 3L airflow was used. Decreases in arterial oxygenation measured by pulse oximetry could be treated by switching to supplementary oxygen. The PCS pump (IVAC 5000 PCAM-pump, Cardinal Health, Dublin, UK) was prepared with prepacked code-labeled syringes that contained $50 \mathrm{ml}$ of propofol $(14.2 \mathrm{mg} / \mathrm{ml})$ or propofol + alfentanil $(14.2 \mathrm{mg} / \mathrm{ml}+0.125 \mathrm{mg} / \mathrm{ml})$. According to a randomization template using blocks of six, patients were numbered consecutively and the syringes were switched between the patients. A nurse not involved in the study or the care for 
the patients kept the computed code key, and was also responsible for preparing the syringes. After the study had finished the code was broken.

Data and interventions were recorded at baseline, every fifth minute or when the pre-set safety limits were breached. Detailed data from BIS were collected after procedures. Pre-set limits for the vital measurements were defined so that specific interventions could be made: 1) respiratory rate less than 8 breaths/minute, patients were encouraged to breathe; 2 ) oxygen saturation of less than $90 \%$ was treated with an oxygen flow of $3 \mathrm{~L} /$ minute; 3 ) an obstructed airway was handled with chin lift; 4) > 30 seconds episodes of apnea were handled with ventilation by mask; 5) bradycardia of less than 40 beats/minute were treated with atropine $0.5 \mathrm{mg}$; 6) systolic blood pressure less than $90 \mathrm{mmHg}$ were treated with ephedrine 5 $\mathrm{mg} ; 7$ ) if conditions for operation were impaired or impossible, patients were encouraged to make multiple pushes on the delivery button to deepen the sedation; and 8) if access continued to be impaired, supplementary doses of propofol $10-20 \mathrm{mg}$ were given.

Before infiltration of local anesthesia, the patients were instructed to press the dose button several times until they felt sedated, and after that they used the sedation system as they liked. Each dose delivered propofol $4.25 \mathrm{mg}$, with or without alfentanil $0.0375 \mathrm{mg} .{ }^{17}$ No lock-out period was used and capacity of the pump restricted the maximum dose count to 5/minute. Doses given and doses not given (patient's demand during period of infusion of doses) were recorded by the pump. Local anesthesia with $1.25 \mathrm{mg} / \mathrm{ml}$ bupivacaine $30-40 \mathrm{ml}$ was used for vaginal reconstructive procedures. To reduce pain over a larger area for incontinence surgery, $5 \mathrm{mg} / \mathrm{ml}$ mepivacaine $40 \mathrm{ml}$ including $5 \mu \mathrm{g} / \mathrm{ml}$ epinephrine was diluted with saline $60 \mathrm{ml}$. At the end of the procedure, the surgeon estimated the adequacy of access and visibility: $1=$ procedure done with no limitations of view or access; $2=$ some limitations, but they did not influence quality, or speed, or both; $3=$ view and access limited to the extent 
that the quality or speed of the operation, or both, was influenced; and 4=operation not possible. Post-operatively the patients were supervised in the recovery room for at least 90 minutes before they were discharged.

\section{Statistical analysis}

To aid the statistical analysis we used Statistica ${ }^{\circledR}$ version 10 (Stat Soft Inc, Tulsa, USA). The significances of differences in the incidences across groups were assessed using the chi square test. Cardiopulmonary data were compared using Student's $t$ test. Comparative analyses between the time intervals of 1 to 10 minutes and 15 to 30 minutes for the two groups were made using repeated analysis of variance (ANOVA). These intervals were chosen because clear changes in cardiopulmonary signs appeared within the first 10 minutes of sedation. Probabilities of less than 0.05 were accepted as significant. 


\section{Results}

\section{Data about the PCS}

Patients in the propofol group used the pump more often, as the counts of both delivered and demanded doses were higher (Table 2). The pump was used most often during the first 3 minutes. During the following 12 minutes the curve of delivered doses flattened out, followed by a period of attenuating use. There was no significant difference in the ratio of demanded and delivered doses between the groups. When the ratios were compared for the four different types of procedures, those being treated for incontinence had a higher ratio $(p=0.045)$; the propofol group had a mean ratio of 1.46 (range $1-2.56$ ) and the propofol/alfentanil group of 1.26 (range $1-1.63$ ).

\section{Aspects of safety}

Sedation with propofol/alfentanil resulted in significantly decreased oxygen saturation compared with propofol alone during both periods (1-10 and 10-30 minutes; $p<0.001$ and $p=0.002$, respectively). Propofol/alfentanil also reduced respiratory rate during the first and second periods, compared with propofol alone ( $p<0.001$ for both periods). There were no differences between the two when the group data were compared without taking account of changes over time (Table 3$)$. 
$10(20)$

Table 2. Number of doses and doses of drugs from propofol and propofol/alfentanil groups and data on time for the procedures. Data are presented as number, mean (SD) and range.

\begin{tabular}{|c|c|c|c|c|c|c|}
\hline & & \multicolumn{2}{|l|}{$\begin{array}{l}\text { Propofol } \\
n=76\end{array}$} & \multicolumn{2}{|c|}{$\begin{array}{l}\text { Propofol/alfentanil } \\
\mathrm{n}=79\end{array}$} & \multirow[t]{2}{*}{$P$ value } \\
\hline \multirow{2}{*}{\multicolumn{7}{|c|}{ Number of doses }} \\
\hline & & & & & & \\
\hline & Demanded & $61(21)$ & & $46(12)$ & & 0.02 \\
\hline \multirow[t]{2}{*}{ Propofol } & Delivered (mg) & $182(84)$ & $21-486$ & $145(117)$ & $30-366$ & $<0.01$ \\
\hline & Demanded (mg) & $258(149)$ & $21-741$ & $196(117)$ & $30-673$ & 0.02 \\
\hline \multirow[t]{2}{*}{ Alfentanil } & Delivered (mg) & & & $1.27(0.60)$ & $0.26-3.23$ & \\
\hline & Demanded (mg) & & & $1.73(1.03)$ & $0.26-5.93$ & \\
\hline \multicolumn{2}{|c|}{ Ratio demanded:delivered } & 1.42 & & 1.35 & & 0.31 \\
\hline \multicolumn{2}{|c|}{ Preparing time (min) } & $9.7(3.6)$ & & $8.7(3.6)$ & & 0.06 \\
\hline \multicolumn{7}{|c|}{ Operating time (min) } \\
\hline & All & $33(14.8)$ & & $29(16.2)$ & & 0.07 \\
\hline & Incontinence & $25(10.1)$ & & $21(8.0)$ & & 0.13 \\
\hline & Anterior repair & $25(7.0)$ & & $26(12.0)$ & & 0.46 \\
\hline & Posterior repair & $36(10.5)$ & & $35(9.4)$ & & 0.65 \\
\hline & Combinations & $48(15.5)$ & & $56(24.7)$ & & 0.29 \\
\hline \multicolumn{7}{|c|}{ Additional sedative given } \\
\hline & All & 8 & & 2 & & 0.04 \\
\hline & Incontinence & 3 & & 2 & & \\
\hline & Posterior repair & 2 & & 0 & & \\
\hline & Combinations & 3 & & 0 & & \\
\hline \multicolumn{2}{|c|}{ Conditions for operation } & 84 & & 81 & & \\
\hline & Good & 69 & & 77 & & \\
\hline & Limited/not possible & 15 & & 4 & & 0.02 \\
\hline & Incontinence & 5 & & 2 & & \\
\hline & Anterior repair & 1 & & 0 & & \\
\hline & Posterior repair & 4 & & 0 & & \\
\hline & Combinations & 5 & & 2 & & \\
\hline
\end{tabular}


Table 3. Data from operative surveillance and interventions. Results are expressed as mean (SD), number and range.

\begin{tabular}{|c|c|c|c|c|c|}
\hline & \multicolumn{2}{|l|}{$\begin{array}{l}\text { Propofol } \\
n=76\end{array}$} & \multicolumn{2}{|c|}{$\begin{array}{l}\text { Propofol/alfentanil } \\
\mathrm{n}=79\end{array}$} & \multirow{2}{*}{$\begin{array}{l}P \text { value } \\
0.03\end{array}$} \\
\hline Bispectral index & $85(10.3)$ & $40-100$ & $89(9.2)$ & $32-100$ & \\
\hline Systolic blood pressure $(\mathrm{mmHg})$ & $121(4.7)$ & $90-190$ & $122(3.5)$ & $84-206$ & 0.37 \\
\hline Heart rate (beats/min) & $70(9.9)$ & $43-98$ & $71(10.2)$ & $38-108$ & 0.21 \\
\hline $\mathrm{SpO}_{2}(\%)$ & $96(2.9)$ & $85-100$ & $95(4.1)$ & $58-100$ & $0.79^{1}$ \\
\hline $\mathrm{P}_{\mathrm{tc}} \mathrm{CO}_{2}(\mathrm{mmHg})$ & $5.6(1.1)$ & $3.3-9.9$ & $6.0(1.2)$ & $3.3-9.9$ & $<0.01$ \\
\hline $\mathrm{ETCO}_{2}(\mathrm{mmHg})$ & $2.95(0.91)$ & $1.0-7.2$ & $3.30(0.79)$ & $1.5-6.0$ & $<0.01$ \\
\hline Respiratory rate (breaths/min) & $16(3.1)$ & $8-25$ & $14(3.5)$ & $0-22$ & 0.56 \\
\hline Oxygen given & 21 & & 52 & & $<0.01$ \\
\hline Encouraged to breathe & 27 & & 59 & & $<0.01$ \\
\hline Chin lift & 0 & & 6 & & 0.02 \\
\hline Mask ventilation & 0 & & 5 & & 0.03 \\
\hline
\end{tabular}

\footnotetext{
${ }^{1}$ Fifty-two of the 79 patients in the propofol/afentanil group with reduced oxygen saturation were given supplementary oxygen.
}

Patients were sedated more heavily if they took propofol alone, according to the bispectral index; $p=0.04$ for 5-10 minutes and $p<0.001$ for $10-30$ minutes. Five patients in the propofol/alfentanil group became apneic, with reduced values for oxygen saturation. The OAA/S for evaluation of the state of sedation defined these five patients as heavily sedated as they did not respond to verbal stimuli (OAA/S level 2). All remaining patients were rousable 
(OAA/S levels 3 to 5). The five heavily sedated patients had to be manually ventilated to treat their apnea and desaturation, in contrast to the patients given propofol alone, all of whom breathed spontaneously. Apnea developed only at the beginning of sedation (1-10 minutes) after a period of multiple dose demands in preparation for infiltration of local anesthesia. In three cases the procedure had not yet been started, and in the two remaining patients the infiltration of local anesthesia had just been completed. These five patients had lower body mass, but did not differ in age or demand:delivery ratio from the rest of the patients in the propofol/alfentanil group. They started breathing within a minute, and two of them continued to use the pump. One patient's bradycardia and low blood pressure was treated with atropine $0.5 \mathrm{mg}$ and ephedrine $5 \mathrm{mg}$. In the remainder the cardiovascular state was stable.

Data from respiratory surveillance showed that the addition of alfentanil to propofol increased the transcutaneous and end tidal levels of carbon dioxide, and required intervention by the nurse anesthetist. Table 3 shows the differences. All interventions took place within the first 13 minutes of sedation.

Measurements of heart rate and systolic arterial blood pressure show that cardiovascular stability was maintained throughout the period of sedation. From 1004 values of systolic blood pressure that were measured, 15 patients had values between 90 and 100 $\mathrm{mmHg}$, and one a single value less than $90 \mathrm{mmHg}$. This patient was treated with ephedrine, and with atropine for bradycardia ( $<40$ beats/minute). This was the only case of bradycardia detected.

\section{Details of the procedures}


The addition of alfentanil influenced the ease of the operation $(\mathrm{p}=0.02)$, although the operation time was unaffected (Table 2). For 10 patients the operation was not possible with PCS, and progress was secured with additional doses of propofol given by the nurse anesthetist. For nine of the remaining 155 patients (two in the propofol/afentanil group) who used PCS for the whole procedure, the operation was done with some limitations of both view and access. For one of these 9 patients the quality and the speed of operating were affected. Six of the 10 patients who were given additional doses of propofol were affected during the first half of the study period. The surgeons' individual estimation of whether they were not able to operate, and whether access was affected, were numerically similar (surgeon A to E and not possible/with limitation): senior surgeon A - 4/3, senior surgeon B - 4/3, surgeon C $1 / 2$, surgeon D - 1/1, and surgeon E - 0/0.

The treatment of incontinence and combined procedures were the most likely to fail, and were also those with more limited surgical access. For the treatment of incontinence, patients were asked to cough or bear down while adjustment was made to the tension cord; one patient did not manage to cooperate and cough. 


\section{Discussion}

The main result of this investigation is that the addition of alfentanil to propofol as PCS made the treatment easier, and fewer supplementary doses of propofol given by the nurse anesthetist were needed. But alfentanil also contributed to an increased need for attention and intervention from the anesthetic professional to maintain the patient's safety. Interventions and supplementary oxygen were needed significantly more often in the alfentanil/propofol group. In this case our hypothesis was confirmed.

In most of the studies regarding PCS for procedural sedation, either propofol alone or propofol and an opioid have been used. ${ }^{8}$ Adding opioids seem to contribute to effectiveness and ease of treatment, with minor or no need for interventions. ${ }^{15,16}$ The use of alfentanil in our study was based on reported respiratory depression with remifentanil, ${ }^{9}$ in combination with concurrent local anaesthesia infiltration. Combinations of sedative and opioids for PCS are possibly required for uncomfortable procedures where the painful stimulus is constant. Effective peripheral blocks and sedatives together may present challenging problems, although local anaesthesia together with propofol PCS seems safe. ${ }^{17,18}$ Both fluctuating stimuli, and waning need for sedation together with control of pain, may make the combined use of propofol and opioids difficult, and a rapid reduction in stimuli can easily lead to over-sedation. The propofol/alfentanil regimen that we used impair safety, which also was confirmed for incontinence surgery in which target-controlled infusion of propofol and remifentanil resulted in apneic episodes, reduced respiratory rate, oxygen desaturation, and the need for close monitoring. ${ }^{2}$ Our use of the same mixtures for gynecological treatment as for burn care ${ }^{19}$, display problems with generalizability, and to ensure safety, tuning of the PCS system is needed. ${ }^{8}$ 
Usually surveys describe a preset loading dose that is infused before the patient uses the PCS. Loading doses that have been used have been calculated from pharmacokinetic modelling that estimated the effect of concentrations of propofol at the site,${ }^{16}$ from weight, ${ }^{20}$ or from undefined preset calculations ${ }^{10}$. We prefer that the patients themselves are responsible for induction, as they get feedback from pressing on the delivery button. Using propofol alone this strategy seems safe, although we could find no supporting evidence for either method. Possibly it may be of advantage to exclude alfentanil from the PCS pump and give it before start of the procedure, as a titrated reduced single dose, adjusted to age, weight or other variables of importance. But there are also a need for randomized studies of the optimal dose of propofol and its effect on safety and the need for interventions. With no lockout period, propofol doses of $3.33 \mathrm{mg},{ }^{21}$ and $4 \mathrm{mg},{ }^{22}$ has been used, and with a lock-out period of one minute doses of $10 \mathrm{mg},{ }^{23} 17 \mathrm{mg}^{24}$, and $20 \mathrm{mg}^{20}$. Both strategies reported episodes of hypoxemia and required manipulation of the patients' airway to avoid serious events.

We did not have a learning curve through the survey period or a surgeondependent outcome, and are firmly of the opinion that the difference found in operating conditions was an effect from the actual drugs. One can discuss whether the surgeons after a few months of the study really were blinded to the drugs used, but there were at least no obvious differences in procedural failures between the first and second study periods. Two limitations of this trial are the heterogeneous nature of the patients when it comes to surgical diagnosis and the limited numbers of patients studied. The four different procedures were chosen as they are relatively easy to do with PCS. Posterior repair and combination procedures require longer operating time, and are dependent on the patient being relaxed. Discomfort in the legs from positioning may lead to movement, usually starting after a period 
of at least half an hour. All procedures included the initial infiltration of local anesthesia, although it was given differently depending on the operation, and all patients were treated according to the same protocol and the five surgeons had experience of all the different procedures. As far as we know, this is the first study that has examined PCS for outpatient gynaecological treatment, and for that reason we included all categories of procedures done during one year.

In conclusion, PCS using propofol alone seems to be safe for the patient. The addition of an opioid increases the risk for respiratory problems and an anaesthetic specialist must be present to monitor the patient and to deal with this problem if it arises. However, our study also shows that the addition of alfentanil to propofol PCS facilitates surgery. 


\section{Acknowledgement}

The study was conducted with professional support from the staff at the Out patient clinic of Gynaecology, Linköping University Hospital, 58185 Linköping, Sweden

This survey was funded by the Department of Anesthesiology and Intensive Care, Linköping University Hospital, 58185 Linköping, Sweden

The authors have no conflicts of interest. 


\section{References}

1 Axelsen SM, Bek KM: Anterior vaginal wall repair using local anaesthesia. Eur J Obstet Gynecol Reprod Biol 2004; 112: 214-6.

2 Winton AL, Eastwood J, Powell MC, Norris AM: An evaluation of conscious sedation using propofol and remifentanil for tension-free vaginal tape insertion. Anaesthesia 2008; 63: 932-7.

3 Buchsbaum GM, Albushies DT, Schoenecker E, Duecy EE, Glantz JC: Local anesthesia with sedation for vaginal reconstructive surgery. Int Urogynecol J Pelvic Floor Dysfunct 2006; 17: 211-4.

4 Segal JL, Owens G, Silva WA, Kleeman SD, Pauls R, Karram MM: A randomized trial of local anesthesia with intravenous sedation vs general anesthesia for the vaginal correction of pelvic organ prolapse. Int Urogynecol J Pelvic Floor Dysfunct 2007; 18: 807-12. Practice guidelines for sedation and analgesia by non-anesthesiologists. Anesthesiology 2002; 96: 100417. Knape JT, Adriaensen H, van Aken H, Blunnie WP, Carlsson C, Dupont M, Pasch T: Guidelines for sedation and/or analgesia by non-anaesthesiology doctors. Eur J Anaesthesiol 2007; 24: 563-7. Wehrmann T, Riphaus A: Sedation with propofol for interventional endoscopic procedures: a risk factor analysis. Scand J Gastroenterol 2008; 43: 368-74.

Atkins JH, Mandel JE: Recent advances in patient-controlled sedation. Curr Opin Anaesthesiol 2008; 21: 759-65. Joo HS, Perks WJ, Kataoka MT, Errett L, Pace K, Honey RJ: A comparison of patient-controlled sedation using either remifentanil or remifentanil-propofol for shock wave lithotripsy. Anesth Analg 2001; 93: 1227-32. pethidine versus propofol and fentanyl patient controlled sedation/analgesia for upper gastrointestinal tract ultrasound endoscopy: a prospective randomized controlled trial. Dig Liver Dis 2007; 39: 1024-9. Hwang J, Jeon Y, Park HP, Lim YJ, Oh YS: Comparison of alfetanil and ketamine in combination with propofol for patient-controlled sedation during fiberoptic bronchoscopy. Acta Anaesthesiol Scand 2005; 49: 1334-8. 

randomized, controlled, double-blind trial of patient-controlled sedation with propofol/remifentanil versus midazolam/fentanyl for colonoscopy. Anesth Analg 2008; 106: 434-9, table of contents. Haynes AB, Weiser TG, Berry WR, Lipsitz SR, Breizat AH, Dellinger EP, Herbosa T, Joseph S, Kibatala PL, Lapitan MC, Merry AF, Moorthy K, Reznick RK, Taylor B, Gawande AA: A surgical safety checklist to reduce morbidity and mortality in a global population. N Engl J Med 2009; 360: 491 9. Chernik DA, Gillings D, Laine H, Hendler J, Silver JM, Davidson AB, Schwam EM, Siegel JL: Validity and reliability of the Observer's Assessment of Alertness/Sedation Scale: study with intravenous midazolam. J Clin Psychopharmacol 1990; 10: 244-51. Mazanikov M, Udd M, Kylanpaa L, Lindstrom O, Aho P, Halttunen J, Farkkila M, Poyhia R: Patientcontrolled sedation with propofol and remifentanil for ERCP: a randomized, controlled study. Gastrointest Endosc 73: 260-6.

Mandel JE, Lichtenstein GR, Metz DC, Ginsberg GG, Kochman ML: A prospective, randomized, comparative trial evaluating respiratory depression during patient-controlled versus anesthesiologistadministered propofol-remifentanil sedation for elective colonoscopy. Gastrointest Endosc 72: 112-7. Yoon HD, Yoon ES, Dhong ES, Park SH, Han SK, Koo SH, Kim WK: Low-dose propofol infusion for sedation during local anesthesia. Plast Reconstr Surg 2002; 109: 956-63. Morley HR, Karagiannis A, Schultz DJ, Walker JC, Newland HS: Sedation for vitreoretinal surgery: a comparison of anaesthetist-administered midazolam and patient-controlled sedation with propofol. Anaesth Intensive Care 2000; 28: 37-42.

Nilsson A, Steinvall I, Bak Z, Sjoberg F: Patient controlled sedation using a standard protocol for dressing changes in burns: patients' preference, procedural details and a preliminary safety evaluation. Burns 2008; 34: 929-34.

Bell A, Lipp T, Greenslade J, Chu K, Rothwell S, Duncan A: A randomized controlled trial comparing patient-controlled and physician-controlled sedation in the emergency department. Ann Emerg Med 56: 502-8.

Thorpe SJ, Balakrishnan VR, Cook LB: The safety of patient-controlled sedation. Anaesthesia 1997; 52: $1144-50$. 
22 Oei-Lim VL, Kalkman CJ, Makkes PC, Ooms WG: Patient-controlled versus anesthesiologistcontrolled conscious sedation with propofol for dental treatment in anxious patients. Anesth Analg 1998; 86: 967-72.

23 Yun MJ, Oh AY, Kim KO, Kim YH: Patient-controlled sedation vs. anaesthetic nurse-controlled sedation for cataract surgery in elderly patients. Int J Clin Pract 2008; 62: 776-80.

24 Rodrigo MR, Irwin MG, Tong CK, Yan SY: A randomised crossover comparison of patient-controlled sedation and patient-maintained sedation using propofol. Anaesthesia 2003; 58: 333-8. 